\title{
Factors Affecting Recombinant Frequency in Protoplast Fusions of Streptomyces coelicolor
}

\author{
By DAVID A. HOPWOOD AND HELEN M. WRIGHT \\ John Innes Institute, Colney Lane, Norwich NR4 $7 U H$
}

(Received 18 September 1978)

\begin{abstract}
The optimum concentration of polyethylene glycol 1000 (PEG) for the production of recombinants through protoplast fusion in Streptomyces coelicolor was about $50 \%(\mathrm{w} / \mathrm{v})$. The addition of $14 \%$ (v/v) dimethyl sulphoxide to the fusion mixture enhanced recombination frequencies, but only at sub-optimal PEG concentrations. After treatment of protoplasts with $50 \%$ PEG for $1 \mathrm{~min}$, the frequency of recombinants in a multi-factor 'cross' sometimes exceeded $20 \%$ of the total progeny. The frequency of recombinants in the progeny could be significantly enhanced by ultraviolet irradiation of the parental protoplast suspensions immediately before fusion.
\end{abstract}

\section{INTRODUCTION}

High proportions of recombinant progeny arise in intra-strain mixtures of genetically marked streptomycete protoplasts allowed to regenerate after treatment with polyethylene glycol (Hopwood et al., 1977; Baltz, 1978). Up to $17 \%$ of recombinant progeny were found in non-selective analysis of six-factor crosses in Streptomyces coelicolor, and significant proportions of fusions gave rise to recombination between the genomes of three or four parental strains (Hopwood \& Wright, 1978). In our previous work we adopted the techniques of protoplast preparation and regeneration developed by Okanishi et al. (1974) and fusion conditions found to be optimal for animal cells (Hales, 1977; Pontecorvo et al., 1977). In this paper we describe the effects of various factors on recombination frequencies, including the use of ultraviolet irradiation of parental protoplasts immediately before fusion as a means of increasing, even further, the proportion of recombinants amongst the viable progeny derived from protoplast fusions.

\section{METHODS}

Bacterial strains. Four derivatives of Streptomyces coelicolor A3(2), all lacking both the SCP1 and SCP2 sex factors, were used, carrying genetic markers as follows: M124, proA1 argA1 cysD18; M130, hisA1 uraA1 strA1; 2692, proA1 argA1; E104, hisA1 uraAl cysD18 strA1.

Fusions and cultural conditions. Standard conditions were those described by Hopwood \& Wright (1978); variations are indicated where relevant.

Ultraviolet (u.v.) irradiation. Protoplast suspensions in $5 \mathrm{ml}$ medium $\mathrm{P}$ were irradiated, with constant agitation, at a dose rate of approximately $4.4 \mathrm{~W} \mathrm{~m}^{-2}$. 


\section{RESULTS}

\section{Effect of plating density of regenerating protoplasts}

In some streptomycetes, notably Streptomyces acrimycini (Hopwood et al., 1977), recombination frequencies after protoplast fusion are low when dense platings of fused protoplasts are allowed to regenerate into confluent cultures. The most likely explanation is that colonies developing from the minority of non-protoplasted mycelial fragments in the protoplast suspensions, which are of exclusively parental genotypes, inhibit the more slowly developing colonies derived from regenerated fused protoplasts, which alone contain recombinants. In $S$. coelicolor, and three other species, no such effect was seen; high recombination frequencies occurred in the spore progeny of confluent regenerated fused protoplasts (Hopwood et al., 1977).

In later work with $S$. coelicolor, probably because of some uncontrolled variation in the composition of the $\mathrm{R} 2$ regeneration medium, the central areas of cultures on regeneration plates derived from undiluted suspensions of fused protoplasts sometimes consisted of uniformly sized, precociously developing colonies characteristic of non-protoplasted units, which had inhibited the development of regenerated protoplasts (Fig. 1). At sufficient dilution, the cultures consisted of well-sporulating colonies derived from protoplasts. For maximal recombinant frequencies, spores were therefore harvested only from regeneration plates with between 2000 and 50000 colonies.

\section{Effect of lytic enzyme no. 2 in protoplast preparation}

In the procedure of Okanishi et al. (1974), protoplasts are prepared from liquid-grown mycelium by digesting the cell walls with a mixture of lysozyme and 'lytic enzyme no. 2', a preparation made by the Kyowa Hakko Kogyo Co. of Tokyo and containing $\mathrm{N}$-acetylmuramyl-L-alanine-amidase, peptidase and endopeptidase activities. This material, an incompletely soluble brownish powder, was avoided in the preparation of protoplasts for transformation by plasmid DNA (Bibb et al., 1978) in case it contained DNAase activity.

We tested the effect on recombination frequencies in fused protoplasts of omitting lytic enzyme no. 2 from the enzyme solution used in their preparation. Release of protoplasts from the mycelial mass was slower with lysozyme alone than with the mixture of both enzymes, but recombination frequencies were not very different (Table 1). In experiments 2 and 3, recombinants were rather more frequent when lytic enzyme no. 2 was present during protoplast formation, while in experiment 1 the situation was reversed. It therefore appears that use of lytic enzyme no. 2 has little or no effect on the propensity of the protoplasts to fuse. Lytic enzyme no. 2 alone failed to give rise to macroscopically detectable release of protoplasts from the mycelium.

\section{Effects of polyethylene glycol concentration, presence of dimethyl sulphoxide and time of treatment on recombinant frequencies}

In the standard fusion treatment (Hopwood \& Wright, 1978), mixed protoplast pellets were exposed to $1 \mathrm{ml}$ of approximately $40 \%$ (w/v) polyethylene glycol (PEG) 1000 in the presence of $14 \%(\mathrm{v} / \mathrm{v})$ dimethyl sulphoxide (DMSO) for $1 \mathrm{~min}$. Addition of an equal volume of $25 \%$ PEG solution gave a subsequent exposure to approximately $33 \%$ PEG (and $7 \%$ DMSO) for $3 \mathrm{~min}$, and further dilution with $4 \mathrm{ml}$ of buffer reduced the PEG concentration to about $10 \%$ during a centrifugation step before plating on regeneration medium.

Aspects of the standard treatment were varied in fusions of strains E104 and 2692. Recombinant frequencies were assessed by plating spore suspensions from populations of regenerated protoplasts on the two media each capable of recovering a parental genotype, and on two of the several possible media selective for recombinants. The sum of colony counts on the latter two media was divided by the sum of counts on the former two to give a 


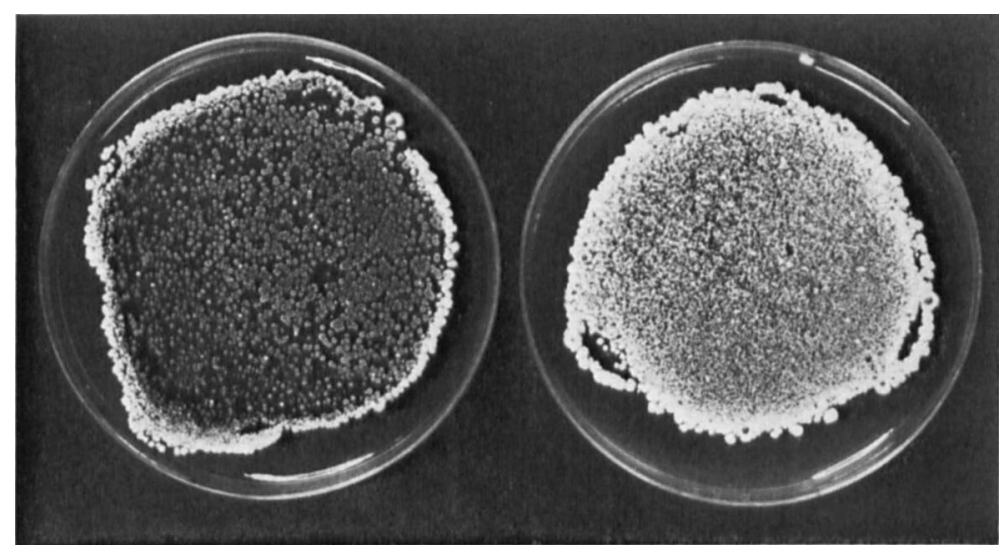

Fig. 1. Regeneration of fused protoplasts of strains M124 and M130: left, $10^{\circ}$ dilution; right, $10^{-1}$ dilution. Note the inhibition, on the left-hand plate, of regenerating protoplast colonies by precociously developing colonies derived from non-protoplasted plating units.

\section{Table 1. Comparison of recombinant frequency for protoplasts prepared} with and without lytic enzyme no. 2

The cross was M124 $\times$ M130.

$\left.\begin{array}{clcccc}\text { Expt no. } & \multicolumn{1}{c}{\text { Treatment }} & \begin{array}{c}\text { No. of } \\ \text { colonies } \\ \text { tested }\end{array} & \begin{array}{c}\text { Recom- } \\ \text { binants }\end{array} & \begin{array}{c}\text { Percentage } \\ \text { of recom- } \\ \text { binants }\end{array} & \text { Probability* } \\ 1 & \text { Lysozyme only } & 645 & 19 & 2 \cdot 9 & 0.07 \\ \multirow{2}{*}{2 \dagger} & \text { Lysozyme+lytic enzyme } & 587 & 8 & 1 \cdot 3 & 0 \\ \multirow{2}{*}{3} & \text { Lysozyme only } & 372 & 39 & 10 \cdot 5 & 0.02 \\ & \text { Lysozyme+lytic enzyme } & 371 & 62 & 16 \cdot 7 & 0 \\ & \text { Lysozyme only } & 183 & 24 & 13 \cdot 1 \\ & \text { Lysozyme+lytic enzyme } & 185 & 38 & 20 \cdot 6\end{array}\right\}$

* Significance of difference between experiments with and without lytic enzyme no. 2 .

$\dagger$ Data from Hopwood \& Wright (1978).

measure of the recombinant frequency, which was of course an underestimate since only certain classes of recombinants were recovered.

The dramatic effect of PEG concentration on recombinant frequency is apparent in Fig. 2, which summarizes the results of experiments done in the absence of DMSO. Essentially the same results were obtained with a 1 min exposure to PEG, whether or not this was followed by a 3 min treatment at a reduced PEG concentration before the final dilution step. No difference was seen with a 1 or 3 min primary exposure to PEG. Moreover, the optimal recombination frequencies in these experiments, in which DMSO was not used, were as high as any ever observed with DMSO present. In summary, this series of experiments showed that a $1 \mathrm{~min}$ exposure to $50 \% \mathrm{PEG}$, in the absence of DMSO, and followed by immediate dilution to $10 \%$ PEG was capable of promoting maximal recombinant frequencies.

A further series of experiments tested the indication in Fig. 2 of a slight fall in recombinant frequency when the PEG concentration was increased from 50 to $60 \%$. In these experiments, in which the overall frequency of recombinants happened to be lower (Fig. 3), there was clearly a reduction in recombination frequency at the highest PEG concentrations of 60 and $70 \%$. The effect of DMSO was also investigated. Its influence was slight, with a small increase in the recombination promoted by DMSO at the lower concentrations of PEG (30 to $40 \%$ ). 


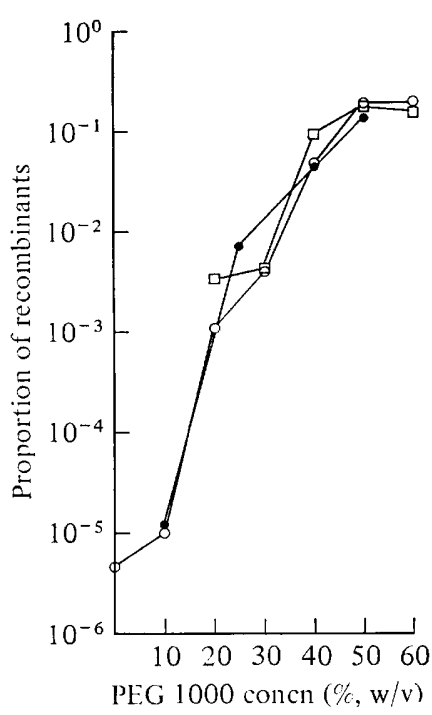

Fig. 2

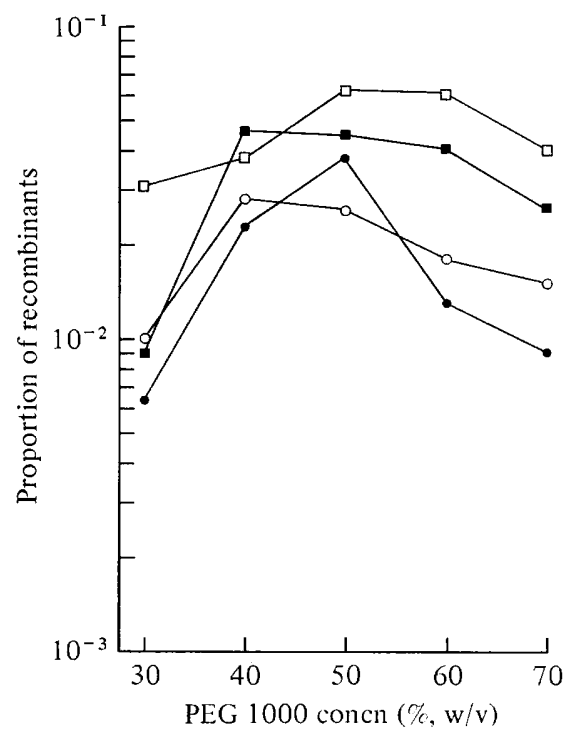

Fig. 3

Fig. 2. Relationship between recombinant frequency and PEG 1000 concentration: $\bigcirc, 1 \mathrm{~min}$ fusion treatment, followed by addition of buffer; $\mathbf{0}, 3$ min fusion treatment, followed by addition of buffer; $\square, 1$ min fusion treatment, followed by addition of PEG at half the original concentration and, after another $3 \mathrm{~min}$, by addition of buffer.

Fig. 3. Relationship between recombinant frequency and PEG 1000 concentration: $\bigcirc, 1 \mathrm{~min}$ fusion treatment, with DMSO;, 1 min fusion treatment, without DMSO; $\square, 3$ min fusion treatment, with DMSO; $\square, 3$ min fusion treatment, without DMSO. Buffer was added immediately after the fusion treatment.

In case the characteristics of recombination in protoplast fusion previously described (Hopwood \& Wright, 1978) had been influenced by the presence of DMSO, these characteristics were investigated in protoplasts fused with 50\% PEG and no DMSO. The distribution of crossovers between map intervals in a six-factor cross was not significantly different from that reported previously. Furthermore, the pattern of recombinants found in a sample of individual colonies arising from a fusion mixture was also the same.

\section{Increased recombinant frequencies after ultraviolet irradiation}

Irradiation of a protoplast suspension in medium $\mathbf{P}$ for $4 \mathrm{~min}$ (about $1.05 \mathrm{~kJ} \mathrm{~m}^{-2}$ ) gave a survival of about $1 \%$ and this dose, or sometimes an intermediate dose of 2 min giving a survival of about $30 \%$, was used in subsequent fusion experiments.

In the first series of experiments, overall recombinant frequencies were low, because spores were harvested from confluent regenerated protoplasts. Recombination was therefore estimated by selective plating of spores from such cultures. In every experiment (Fig. 4), recombinant frequencies were significantly increased by $4 \mathrm{~min}$ of u.v.-irradiation, typically by a factor of about 10 . In later experiments, when higher levels of recombination were the rule, unselected samples of progeny were classified for recombinants. Again, u.v.-irradiation consistently increased the recombinant frequency, inevitably by a smaller factor at higher spontaneous frequencies: from 1.5 to $12.6 \%$; from 12.6 to $25.7 \%$; and, at the highest level, from 19.9 to $38 \cdot 1 \%$ (Table 2).

Not only were recombinant frequencies increased by u.v.-irradiation, but the proportion of recombinants due to multiple crossover events (four or six crossovers compared with two) was also higher (Table 2). In the absence of u.v.-irradiation, $24 \%$ of all recombinants were produced by multiple crossing-over in a six-factor cross (Hopwood \& Wright, 1978); a 


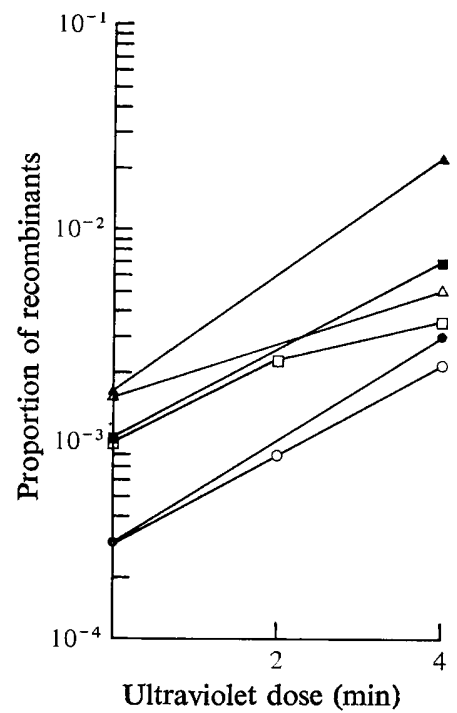

Fig. 4. Effect of ultraviolet irradiation of parental protoplast suspensions on recombinant frequency. The data represent six independent experiments, with protoplast fusion under 'standard' conditions (Hopwood \& Wright, 1978).

Table 2. Effect of ultraviolet irradiation of protoplast suspensions on recombinant frequency and on the proportions of multiple crossover recombinants

Protoplasts were fused under 'standard' conditions (Hopwood \& Wright, 1978).

\begin{tabular}{|c|c|c|c|c|c|}
\hline Parents & $\begin{array}{l}\text { U.v. dose } \\
\text { (min) }\end{array}$ & $\begin{array}{l}\text { No. of } \\
\text { colonies } \\
\text { tested }\end{array}$ & Recombinants & $\begin{array}{l}\text { Percentage of } \\
\text { recombinants }\end{array}$ & $\begin{array}{l}\text { Percentage of } \\
\text { recombinants } \\
\text { with } 4 \text { or } 6 \\
\text { crossovers }\end{array}$ \\
\hline M124×M130* & 0 & 3558 & 400 & $11 \cdot 2$ & 24 \\
\hline $2692 \times \mathrm{E} 104$ & $\begin{array}{l}0 \\
4\end{array}$ & $\begin{array}{l}375 \\
389\end{array}$ & $\begin{array}{r}6 \\
49\end{array}$ & $\begin{array}{r}1 \cdot 5 \\
12 \cdot 6\end{array}$ & $\begin{array}{l}16 \\
31\end{array}$ \\
\hline M124×M130 & $\begin{array}{l}0 \\
4\end{array}$ & $\begin{array}{l}277 \\
369\end{array}$ & $\begin{array}{l}35 \\
95\end{array}$ & $\begin{array}{l}12 \cdot 6 \\
25 \cdot 7\end{array}$ & $\begin{array}{l}26 \\
34\end{array}$ \\
\hline $2692 \times$ E104 & $\begin{array}{l}0 \\
2 \\
4\end{array}$ & $\begin{array}{l}282 \\
286 \\
189\end{array}$ & $\begin{array}{l}56 \\
73 \\
72\end{array}$ & $\begin{array}{l}19 \cdot 9 \\
25 \cdot 5 \\
38 \cdot 1\end{array}$ & $\begin{array}{l}27 \\
40 \\
33\end{array}$ \\
\hline Average & $\begin{array}{c}0 \\
2 \text { or } 4\end{array}$ & & & & $\begin{array}{l}23 \\
35\end{array}$ \\
\hline
\end{tabular}

Table 3. Effect of ultraviolet irradiation of protoplast suspensions on the proportion of individual colonies containing recombinants

Protoplasts were fused under 'standard' conditions (Hopwood \& Wright, 1978).

$\begin{array}{cccc}\text { Parents } & \begin{array}{c}\text { U.v. dose } \\ (\mathrm{min})\end{array} & \begin{array}{c}\text { No. of colonies } \\ \text { tested }\end{array} & \begin{array}{c}\text { Percentage of } \\ \text { colonies con- } \\ \text { taining recom- } \\ \text { binants }\end{array} \\ 2692 \times \text { M10 } & 0 & 98 & 15^{*} \\ 2692 \times \text { E104 } & 4 & 25 & 28 \\ & 0 & 98 & 8^{*} \\ \text { Average } & 4 & 99 & 33 \\ & 0 & 56 & 18 \\ & 2 & 57 & 40 \\ & 4 & 59 & 34 \\ & 6 & 37 & 38 \\ & 0 & & 14 \\ & 2,4 \text { or } 6 & & 35\end{array}$

\footnotetext{
* Data from Hopwood \& Wright (1978).
} 
similar proportion was found in the present work (Table 2). After u.v.-irradiation, the proportion was consistently increased, to an average value of $35 \%$ (Table 2).

An average of $14 \%$ of individual colonies arising from a six-factor protoplast fusion contained recombinants when no u.v.-irradiation was carried out; after u.v.-irradiation, for 2,4 or $6 \mathrm{~min}$, the proportion was increased significantly to an average of about $35 \%$ (Table 3).

\section{DISCUSSION}

When desired genotypes can be selected from a protoplast fusion, optimization of recombinant frequencies may be unimportant, but for many purposes, particularly the construction of complex genotypes involving non-selectable characters in both academic and applied work, the ability to detect such genotypes amongst comparatively small populations of progeny is crucial (Hopwood et al., 1977; Hopwood, 1978). The most important factors affecting recombinant frequencies appear to be the PEG concentration during the fusion step, and conditions determining competition between protoplasts and cells on the regeneration plates.

The degree to which precociously developing colonies - predominantly those from nonprotoplasted units - inhibit later developing colonies and so dilute, with parental genotypes, the recombinant population of progeny from protoplast fusions is both strain- and mediumdependent. In earlier work, we observed this phenomenon with $S$. acrimycini but not $S$. coelicolor, S. lividans, S. parvulus or S. griseus, while Baltz (1978) found it with $S$. fradiae. In later work, it was significant also with $S$. coelicolor (Fig. 1). Its effects can be avoided by minimizing the proportion of non-protoplasted units in the parental suspensions (Baltz, 1978) and by diluting the fusion mixture to give sub-confluent, rather than very dense, populations of colonies.

The optimum concentration of PEG 1000 in the fusion mixture, in the absence of DMSO, was $50 \%$, in striking agreement with the findings for animal cells. As for animal cells, $14 \%$ DMSO in the fusion mixture enhanced the effects of PEG at sub-optimal concentrations (such as 40 or $30 \%$ ), but its use appears to be unnecessary, at least with the comparatively low molecular weight PEG 1000, since optimal recombinant frequencies could be obtained with $50 \%$ PEG alone. The comparatively slight reduction of recombinant frequencies at $60 \%$ PEG 1000 and, even more, at $70 \%$ may well reflect the difficulty of rapidly and uniformly coating the protoplasts with viscous PEG solutions.

The time of exposure of the mixed protoplasts to PEG, at optimal concentrations for fusion, can be very short; we observed no time-dependence of recombinant frequencies over a period of 1 to $3 \mathrm{~min}$, and little or no suggestion that a longer period of exposure could compensate for a sub-optimal PEG concentration. This supports earlier conclusions (Pontecorvo et al., 1977; Hopwood \& Wright, 1978) that establishment of effective fusion sites is very rapid.

Although the complete lytic mixture consisting of lysozyme and lytic enzyme no. 2 (Okanishi et al., 1974) resulted in more rapid protoplast formation, there was no evidence that the protoplasts produced by the action of lysozyme alone were less able to fuse. Baltz (1978) observed recombination in $S$. fradiae and $S$. griseofuscus when protoplasts were prepared with lysozyme only; however, since he recovered recombinants directly on selective regeneration plates, it is hard to compare the efficiency of recombination with that obtained in the present work.

Ultraviolet irradiation of parental protoplasts before fusion certainly increases, by factors up to 10 , the proportion of recombinants amongst the viable progeny. This effect is not due primarily to a stimulation of crossing-over, since the probability of recombinant production when genetically unlike protoplasts fuse approaches $100 \%$ in the absence of u.v.-irradiation (Hopwood \& Wright, 1978). The chief cause is a reduction, as expected, in 
the proportion of colonies arising from single unfused protoplasts, which tend to contain lethal damage. The finding of higher proportions of multiple crossover recombinants is expected on the hypothesis that many recombinants arise by recombining out lethal hits at different loci in different members of the irradiated protoplast preparation. Although the higher recombinant frequencies after u.v.-irradiation might carry a penalty of unwanted mutagenesis in some situations, in industrial strain improvement programmes it might be advantageous to introduce a round of mutagenesis at the same time as a round of recombination (Hopwood, 1978).

\section{REFERENCES}

BALTZ, R. H. (1978). Genetic recombination in Streptomyces fradide by protoplast fusion and cell regeneration. Journal of General Microbiology 107, 93-102.

BiBb, M. J., WaRd, J. M. \& HopwOOD, D. A. (1978). Transformation of plasmid DNA into Streptomyces at high frequency. Nature, London 274, 398-400.

HALES, A. (1977). A procedure for the fusion of cells in suspension by means of polyethylene glycol. Somatic Cell Genetics 3, 227-230.

Hopwood, D. A. (1978). The many faces of recombination. In 3rd International Symposium on the Genetics of Industrial Microorganisms (in the Press). Washington D.C.: American Society for Microbiology.
Hopwood, D. A. \& Wright, H. M. (1978). Bacterial protoplast fusion: recombination in fused protoplasts of Streptomyces coelicolor. Molecular and General Genetics 162, 307-317.

Hopwood, D. A., Wright, H. M., BibB, M. J. \& CoHEN, S. N. (1977). Genetic recombination through protoplast fusion in Streptomyces. Nature, London 268, 171-174.

OKanishi, M., SuzưKI, K. \& Umezawa, H. (1974). Formation and reversion of streptomycete protoplasts: cultural condition and morphological study. Journal of General Microbiology 80, 389-400.

Pontecorvo, G., Riddle, P. N. \& Hales, A. (1977). Time and mode of fusion of human fibroblasts treated with polyethylene glycol (PEG). Nature London 265, 257-258. 